reflexes were normal. The pupils reacted to light and accommodation. The tongue was dirty. There were diarrhora and anorexia, but no vomiling. 'Jhere was a slight history of aleohol and of syphilis contracted six years previously. About ten days after admission his pupils were observed to be unequal. $A$ further examination of his eyes revealed the following facts. 'T'he pupils were unequal, the left circular diameter being $2 \mathrm{~mm}$, and the right, which was vertically oval, about $4 \times 3 \mathrm{~mm}$. Both contracted well to near fixition, but were irresponsive to light. Vision of the right eye was $=y^{6}$, and that of the left $=\frac{6}{6}$. There was slight donble optic neuritis. Three weeks after admission it was noticerl that the patient's right arm was paretic. From this time onwards his condition went stendily from bad to worse, in spite of forty-tive grains of iodide of potassium administered daily. 'There was marked mental deterioration-first, great emotionalism, and then increasing stupidity. Six weeks after achission his state was as follows. He had scarcely any intelligence and passed both urine and foces involuntarily. There were paresis of the muscles of the right side of the face, including the orbicularis palpebrarum, marked exagreration of both pitellar reflexes, with patellar clonus and ankle-clonus on the rimlit sille. Abont seren weeks after his admission his respiration suddenly became slower and stopped. As his pulse was still goof, artificial respiration was continued for about an hour and a half. Several times the artificial respiration was stopped until the radial pulse became almost imperceptible, then, on recommencing the respiration, the pulse regained its former strength. As after an hour and a half the patient made no attempt to breathe the efforts were abandoned.

Necropsy.-Endarteritis of branches of the basilar artery was found, also basal meningitis closing up the foramen of Magendie, and there was a gumma is large as a small hen's-egre in the left frontal lobe surrounded by an area of white softening.

(ASE 6. Cerebellar tumour; internal hydrocephalus.-The patient, a female aged ten years, had had nine months before admission some abdominal symptoms diagnosed as tuberculous peritonitis. On admission the symptoms pointed to caries of the lumbar spint. Six weeks previously she had pain in the hear and back, with "convulsions"; twelve days after admission she had another attack of "convulsions," leaving pain in the hear and back accompanied by strabismus. The pupils were dilated and equal, and there was no paresis. 'the girl regained her previous condition. Nine days later she had another "fit," when respiration ceased, the pulse remaining strong and regular. The heart continued to beat while artificial respiration was carried on for over two hours.

Necropsy.-A tuberculous mass albout the size of a hen's egg, but irregular in shape, was found in the roof of the fourth ventricle, protruding into that cavity and distending it, and at the same time invading the right lobe of the cerebellum. 'The iter was greatly distended, and to a less extent the third and lateral rentricles. A large amount of clear cerebro-spinal fluid escaped when the brain was being removed, through rupture of the dilated stalk of the pineal body.

Remarks-Case 2 presents several very interesting features; the symptoms, which rescmbled a good deal those of caries of the upper cervical rertebræ, were dependent upon a basal meningitis. Probably also the supposed sunstroke five years before was of a similar nature. 'The cause is difficult to divine. It will be noticed that the conjunctival reflex persisted after attempts at respiration had ceasedexactly the opposite to what is observed in poisoning by chloroform and similar drugs. It seems remarkable also that the accessory movements of respiration should have continued after the essential ones had ceased. Another point of interest is the contracted state of the pupils in a patient dying from asphyxia. Perhaps the strangest feature of the whole case is that natural respiration should have recommenced at all, seeing that the cause of its failure still persisted. Case 4 is in one respect the reverse of Case 2, for the conjunctival reflex was lost before the efforts at respiration ceased. Case 5 presents several points of interest. The steady progress of the disease in spite of large doses of iodide of potassium is contrary to the usual experience. The development of such marked mental symptoms in connexion with a lesion of the left frontal lobe is interesting. A very remarkable point is the development of the Argyll-Robertson pupil while the patient was under observation. Apart from locomotor ataxy and general paralysis the phenomenon must bo exceedingly rare. The one feature common to all these cases is that death was in all probability due to the increase in intra-cranial pressure causing paralysis of the respiratory centre in the floor of the fourth ventricle. In four of the cases recovery, complete or partial, was theoretically possible if the immediate cause of death conld have been remored. Hamorrhage, syphilis, and localised tubercle may all be recovered from, while in a fourth case death was clearly caused by a mere blocking of the foramen of Magendie. These are not selccted cases, but are simply taken as they occurred successively. The question obviously suggests itself as to whether anything surgical conld be done in such desperate cases. If the pressure in the fourth ventricle could bo reliever it scems to us that recovery might be possible. If the foramina which connect the ventricles of the brain with the subarachnoid space were patent, then opening of this space would be all that was necessary. If, on the other haml, these were blocked, as occurred in four of our cases, then two possibilities suggest themselves: one is to give temporary relief by tapping one of the lateral ventricles, and the other is to trophine the cerebellar fossa and make an attempt to rupture the roof of the fourth ventricle. No anzsthetic would be needed, but considerable difficulty might be experienced in attempting to operate on the back of the head whilst artificial respiration was being carried on, owing to the position of the patient. It is scarcely likely that ar automatic apparatus such as is used in a physionogica? laboratory would be found in a hospital.

\section{A NEW BOBBIN FOR INTHWTINAL ANASTOMOSIS.}

BY IIERBERT WILLIAM ALLINGHAM, F.R.C.S. ENG.,

SCRGEON TO THLE GRILAT NORTHERT HOSPITAT; ASSISTANT SURGEON TO S'T. GLORGE'S HOSPITAI.

I'T is with some hesitation that I venture to suggest a new bobbin for intestinal anastomosis, which appears to me to supply wants and to obviate faults, or rather disadvantages, noticeable in most of the other bobbins or buttons which have been designed. In my opinion some form of apparatus is necessary to unite hollow viscera one to the other. Now, a bobbin acts as a kind of splint while union is taking place, preventing any contraction or dilatation of the gut at theseat of union, and thus does away with any chance of leaking in the line of suturing. When no form of bobbin has beens used, as in suturing by Mansel's or by Halsted's method, the seat of suturmg has no support, and even a slight dila tation or contraction of the gut may easily allow some leak. between the sutures to occur at the place of union. Again, rest and fixation favour union in the case of viscera, in the same way as with other parts of the body, and hence arises the necessity of a bobbin to secure that rest which is impera tive for the sound joining of intestine to intestine, stomach tos intestine, \&c. It is thus seen that in intestinal anastomosis some plate, bobbin, or button is desirable, if not absolutely necessary.

Before describing my new appliance it mas be allowable for me to point out some of the disadrantages in the plates, bobbins, or buttons which are the most frequently used in intestinal surgery. The bobbin designed by Mr. Mayo Robson appears to be the best, for it is made of decalcifiedl bone, and as it is therefore absorbed there is no fear of its remaining for an indefinite time in the intestinal tract as a foreign body. 'The only disadvantage is that the flanges, or rather edges, at the ends of the bobbin are separated from one another by about three-fourths of an inch ; hence, when viscera are being brought together, it is necessary to use: some kind of suture running from one to the other, a process which takes some time to perform. (See Fig. 1, a.) Moreover, when the viscera have been brought together over the bobbin they can slip from one end of it to the other. At times, indeed, there is a fear of the bobbin slipping out from the seat of union, and this has actually occurred in one of my" cases. Senn's plates appear to allow the edges of the incision in a viscus to fall together, and thus the communications between the viscera are too small later. This arises from the circumstance that while union is taking place there is nothing in the openings to keep them patent. It is obrious that this condition is rendered impossible by Mayo Robson"s 
bobbin Zुor Koy Murphy's putton. With regard the latter there are several objections. It does not seem advisable that a hard metal button should be employed for anastomosis ; for, in the first place, the button may be delayed in the intestine for a very long time, as in Lane's case, in which it did not come away even in 160 days. Again, when one considers the varying sizes of the ileo-cæcal valve it is readily conceivable that the button might be unable to pass the

Fig. 1.

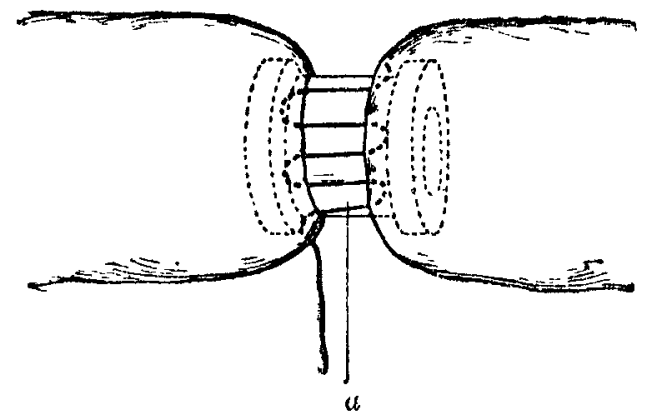

valve and might cause obstruction at that situation. In gastro-enterostomy the button might fall back into the stomach and then be unable to pass the pylorus or be romited through the cesophagus. Further, it is not judicious to press intestines together at their seat of union by a button which, as far as I can see, can come away only by absorption or by sloughing of the pressed parts which have been brought oogether between its two pieces. (Fig. 2,a.) In no other way

Fitr. 2.

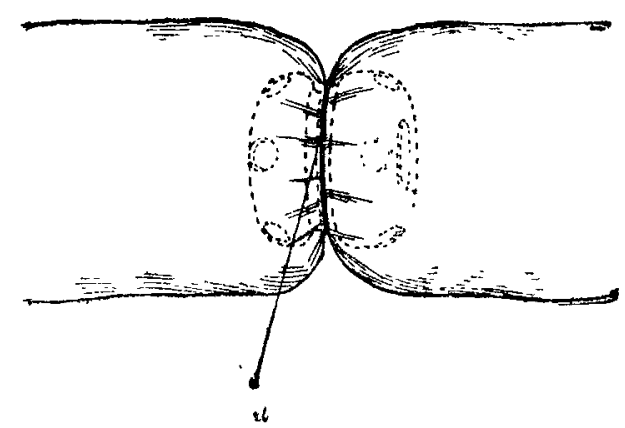

can the button free itself from the intestine at the seat of wnion. No less than five cases have come to my knowledge in which sloughing with perforation took place at the seat of anion, the patients dying from the consequent peritonitis. it is perfectly sound to hold that the intestines at the seat of union should be kept together by pressure, but this pressure must not be too great or too small. Still, it is desirable to devise some mode of maintaining this pressure which will not necessitate any absorption or sloughing in order to free the button when the parts have been sufficiently glued itogether.

It is to remedy the various disadvantages indicated above that I have designed my bobbin. Its principle rests in the fact that it consists of two cones with their apices coming sogether to form the centre. The tubes are of bone or ivory, the shape of two hollow truncated cones with thcir lesser ends together, having the appearance of small dice-boxes. These are carefully decalcified to within about threesixteenths of the centre $(a)$, leaving at the junction of the two cones a hard, unyielding portion unon which any pressure from the sutures is borne. The ends of the tubes are quite soft. There are several sizcs, the most usual being-

\begin{tabular}{|c|c|c|c|c|c|}
\hline $\begin{array}{c}\text { Diameter of } \\
\text { bore. }\end{array}$ & $\begin{array}{l}\text { Diameter } \\
\text { of end } \\
\text { (outside). }\end{array}$ & Length. & $\begin{array}{l}\text { Angle of } \\
\text { cones. }\end{array}$ & Known & $a s-$ \\
\hline$\frac{x}{4}$ inch. & inch. & $1 \frac{1}{4}$ inch. & $150^{\circ}$ & No. 1 & izze. \\
\hline$\frac{3}{8}$, & $1 \quad$, & $1 \frac{1}{2} \quad$, & $140^{\circ}$ & No. 2 & ," \\
\hline$\frac{1}{2}$, & $1 \%$ & $1 \frac{x}{2} \quad "$ & $140^{\circ}$ & No. 3 & $"$ \\
\hline$\frac{3}{4}$, & $1 \frac{2}{4}$ & $1 \frac{1}{2} \quad$, & $140^{\circ}$ & No. 4 & $"$ \\
\hline
\end{tabular}

They can be made in any other sizes reguired, but the above four sizes can always be had without delay from Messr. Krohne and Sesemann, Duke-street, Manchester-square, $W$. This appliance is exceedingly simple and appears to serve all the purposes required of a bobbin or button, for it keeps the parts at absolute rest; can be absorber, as it is made of decalcified bone: and can be liberated without any absorption or sloughing of the marts it unites. Moreover, from its shape it cannot, until the decalcified bone is absorbed, slip away from the seat of union, and when the sutures in each piece of intestine are ticd the parts to be joined must be brought together, and yet no excossive pressure is exerted on the edges which it is desired to connect. $\Lambda$ s the bobbin may be used in various operations, it has been made in different sizes. Those for gall-bladder cases are one-fourth of an inch wide at the narrowest point-viz., the centre (Fig. $3, a$ ); in

IIT. 3.

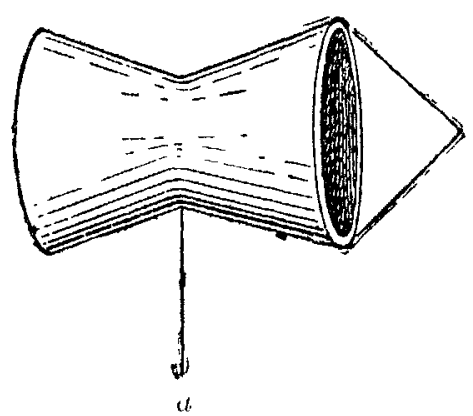

those for small-intestine cases, seeing that the intestinal contents are liquid, the width at the narrowest point need not be more than one-half or three-eighths of an inch. Much larger ones are required for large-intestine cases, as the intestinal contents are solid or semi-solid-viz., three-fourths of an inch. Though the bobbin mav be employed to unite intestine to stomach, gall-bladder to intestine, and indeed in any form of anastomosis, its use may be most conveniently explained by presuming that two pieces of intestine are to be

FIG. 4.

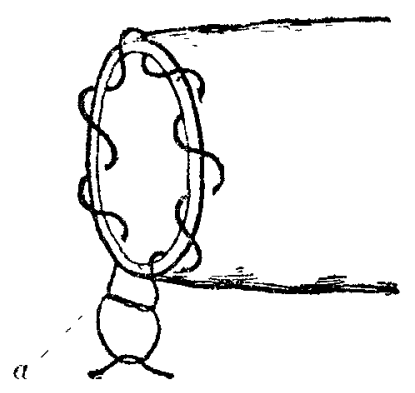

united end to end. Into or round each piece of intestine a fairly stout continuous silk suture is passed, which should include in each stitch the peritoneum, the muscular coat, and the mucous coat (Figs. 4 and 5). Then one end of the bobbin is inserted into one piece, and the suture is pulled tight by a knot twice threaded, so that it will not slip (Fig. 4, a), but the final tie is not made until the other end of the bobbin has been inserted into the other piece of intestine. After this, one of the sutures is tightened up to its utmost; this brings the part down to the centre of the

FIG. 5.

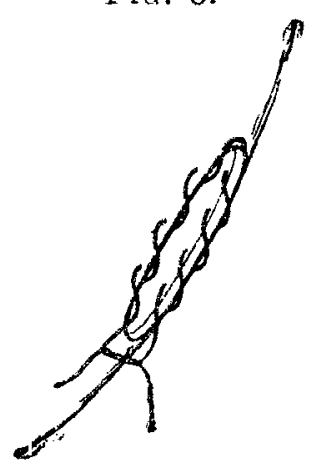

bobbin, for, as the bubbin consists of two cones with their apices pointing to its centre, the tighter the suture is drawn (Fig. 6, a) the more completely must it draw the intestine to the apex of the cone (Fig. $6, b$ ) which has been inserted into it. A similar tying of the other suture brings the other piece of intestine down to the apex of its cone (Fig. 7, a). Thus, from the shape of the bobbin, the parts to be united are brought into exact apposition and at the same time are pressed together. A few Lembert's 
cutures may then be inserted at various points, or a continuous Lembert's suture may be used all round if that be thought necessary. It is wise to scarify the peritonoum of the intestines with a needle for about half an inch round the seat of union. 'This scarifying promotes the exudation of lymph, which acts as a callus (just as in a fracture of bones) round the ends to be united. Iispecially should this be done if no Lembert's sutures have been employed. The intestines when united cannot move in either direction, for the sutures, which are tied up tightly at the narrowest part of their

Fig. 6.

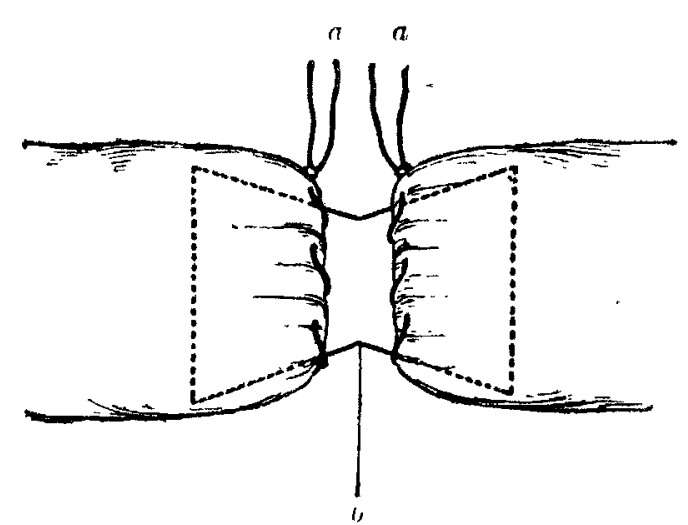

respective cones, naturally cannot slip up to any broader portion; moreover, the bobbin itself cannot possibly alter its position either upwards or downwards.

Murphy's button and Mayo Robson's button are sometimes blocked by solid fæces which have to travel through them for some distance (about an inch). Now, since my bobbin is shaped like an hour-glass, there is an extremely small surface to obstruct the passage of solid matter; this may be represented as being merely the extent of a linei.e., at the meeting of the apices of the cones. This is quickly passed, and then the cones grow wide once more.

\section{FIG. 7 .}

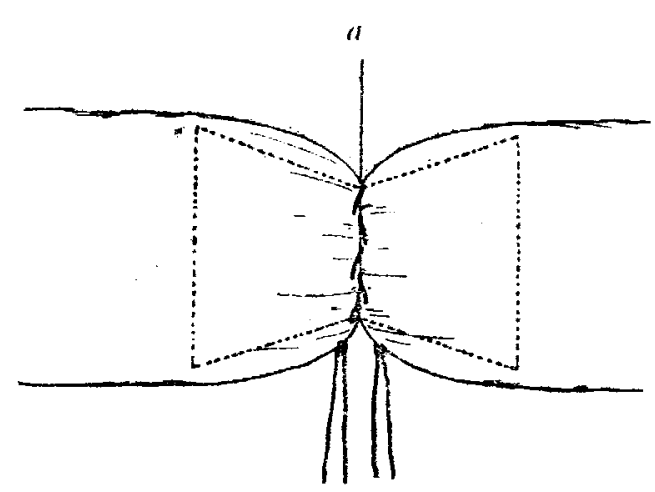

Simplicity is, I think, the characteristic of the bobbin. No complicated suturing is required, nothing being needed except the continuous sutures-one round one end of the divided intestine, and the other round the other end--or, in a similar manner, round the incisions, one in one viscus and the other in the other. Hence it can be applied very rapidly. Further, it cannot slip, and in consequence of its shape the parts to be joined are brought closely together. Lastly, it is absorbed in time and therefore cannot act as a foreign body. I have experimented many times with the bobbin on the dead body and find it is most easy of application, and the operation rapidly carried out. At present I have had only one opportunity of using it upon the living subject, and in this case with excellent results.

Grosvenor-street, W.

Heavy Fines for Adumterating Mrik.-At Southwark Police-court, on Tuesday, Aug. 27th, David Jenkins, of Guy-street, Bermondsey, and Joseph William Bramley, of Weston-street, Bermondsey, were summoned under the Sale of Food and Drugs Act, at the instance of Mr. Henry 'Thomas, inspector to the Bermondsey Vestry, for having unlawfully sold milk adulterated with added water to the extent of 19 and 18 per cent. respectively. The cises having been proved, Mr. Fenwick finerl Jenkins, against whom there were previous convictions, £20 and 12s. $6 d$. costs, and Bramley $£ 3$ and 12s. 6rl. costm.

\section{SPINAT, SOFTENING LIMITED TO THE PARTS SULPLIE]) BY THE I'OSTERIOR ARTERIAI, SYSTEM OF THE CORD.}

BY R. 'I'. WILLIAMSON, M.D. IOND., M.R.C.P., MEDICAI. REGISTRAR, MANCHESTKR ROYAL INIIRMARY, AND ASSISTANY IN MEDTCLNE, OWHAS COLLRGE.

THE spinal cord is supplied with blood at its anterion part chiefly by a long narrow artery, the anterior spinal and at the posterior parts by two long narrow vessels, the posterior spinal arteries. These arteries are reinforced by numerous small arterial twigs coming from the intercostal lumbar and sacral arteries, which enter the spinal canal by: the intervertebral foramina and run along the anterior and posterior nerve roots. A number of small arteries, derived from the vessels on the surface, enter the substance of the spinal cord: the largest of these are the anterior median arteries, which penctrate the anterior median fissure. The exact distribution of these branches within the cord is described in most anatomical text-books. Now the blood supply of the cord may be divided broadly into the anterior and posterior arterial systems; and a transverse section of the cort may be divided roughly into two districts or areas-one supplied by small arteries coming from the anterior arterial system and the other by arteries from the posterior system. The blood supply to the interior of the cord by the anterior spinal arteries is more important than that by the posterior arteries. The distribution of the lesions in a number of spinal diseases is related to the vascular supply, as I have pointed out elsewhere. ${ }^{2}$ A spinal cord which I have recently examined furnishes a beautiful example of the localisation of the lesion: to the part supplied by the posterior arterial system. During life the patient was under the care of Dr. Graham Steell, to whose kindness I am indebted for the opportunity of making: the pathological examination.

A man fifty years of age, suffering from paraplegia, was admitted as an in-pitient to the Manchester Royal Infirmary" on Aug. 29th, 1894. His previous health had been good until three weeks before admission, when he suddenly lost. the use of his left leg immediately before getting into bed in the evening. He had just passed urine and was pulling off his stockings when he found that he was unable to raise the left leg. He thought that the right leg became paralyseds soon afterwards. There was no pain in the back or limbs atw the onset, but the legs felt numbed. He stated, however, that he could feel when anything touched his legs. Very soom after the onset of the paralysis the legs became painful, especially the left, and there had been dull, aching pain, with occasional sharp, shooting pains, in the legs ever since. Retention of urine had been present from the onset and a catheter had been passed daily. The logs had remained completely paralysed from the commencement. The arms had not been affected, and there had been no pain in the back There is no history of syphilis or gonorrhwea or rheumatism. With the exception of two attacks of pleurisy (one eight years and the other twenty years before admission) the previous health has been good, until one month before the onset of the paralysis. At that date he began to feel languid, but was able to attend to his work quite well.

On admission to the infirmary the patient was somewhat wasted. Both leg's were completely paralysed, and the feet and toes were "dropped." The legs were flaccid; the knee-jerks were present; there was no ankle-clonus and the plantar reflex was present on the left side, but was not obtained on the right. The abdominal, epigastric, and cremasteric reflexes were not obtained. A light touch with the head of a pin was not felt on the right leg; a pin prick also was not felt. On the left leg both the point and head of a pin were fest and localised. On the abdomen the head and the point of a pin were not felt on the lower part-up to a point midway between the pubes and umbilicus; above this level botb were felt distinctly. There was no zone of hyperresthesia just above the ancsthesia. The patient could 